\title{
Predicting the Intention to Use Technology in Education among Student Teachers: A Path Analysis
}

\author{
Piret Luik $^{1, *(\mathbb{D})}$ and Merle Taimalu ${ }^{2}$ \\ 1 Institute of Computer Science, University of Tartu, Narva mnt 18, 51009 Tartu, Estonia \\ 2 Institute of Educational Science, University of Tartu, Salme 1a, 50103 Tartu, Estonia; merle.taimalu@ut.ee \\ * Correspondence: piret.luik@ut.ee
}

Citation: Luik, P.; Taimalu, M. Predicting the Intention to Use Technology in Education among Student Teachers: A Path Analysis. Educ. Sci. 2021, 11, 564. https:// doi.org/10.3390/educsci11090564

Academic Editors: Danial Hooshyar, Michael D. Kickmeier-Rust and Nour El Mawas

Received: 16 August 2021

Accepted: 16 September 2021

Published: 21 September 2021

Publisher's Note: MDPI stays neutral with regard to jurisdictional claims in published maps and institutional affiliations.

Copyright: (c) 2021 by the authors. Licensee MDPI, Basel, Switzerland. This article is an open access article distributed under the terms and conditions of the Creative Commons Attribution (CC BY) license (https:// creativecommons.org/licenses/by/ $4.0 /)$.

\begin{abstract}
Teacher education must provide the knowledge and skills necessary for technology integration, but also influence attitudes and beliefs. Little research has been conducted on how knowledge, beliefs, and attitudes predict teachers' intentions to use technology. The aim of this study was to identify how perceived knowledge about technology integration, and beliefs and attitudes towards using technology, impact the intention to use technology among student teachers. The sample consisted of 232 student teachers from the University of Tartu. Data were collected using a questionnaire based on elements of two different models. Validating the technology acceptance scale using a confirmatory factor analysis identified that perceived usefulness was split into two constructs: perceived usefulness for students and perceived usefulness for teachers. Path analysis, as a special type of structural equation modelling, was used to test 11 hypotheses. The results showed that both perceived ease of use and attitude to use have direct effects on intention to use. Still, perceived usefulness for teachers and perceived knowledge displayed an indirect influence. Based on these results, it is important that student teachers should be convinced that technology is easy to use in teaching.
\end{abstract}

Keywords: student teachers; intention to use; knowledge about technology integration; beliefs for using technology; path analysis

\section{Introduction}

In the last decade, increased attention has been paid to the development of digital skills across the entire population, so that each person can use different e-opportunities [1]. The aim of the Education Strategy 2021-2035 [2] in Estonia is that all people have the knowledge, skills, and attitudes to enable them to manage in every area of life. Such an aim certainly requires digital skills today. In the case of teachers, the aim is to develop the skills and willingness to engage in technological integration in teaching. The use of technology is necessary, in the context of teacher professional development and for students, to engage and motivate teachers and students, improve their comprehension, and develop their technological skills [3]. The use of technology provides greater flexibility in teaching, allowing, for example, accounting for different types of intelligence and interests [4]. The COVID pandemic, which began worldwide in spring 2020, has brought this issue even more into focus. School closures and the need for teachers to teach students remotely have contributed to a new situation wherein teachers can no longer choose whether or not to use technology in the teaching process. It is elementary and inevitable in this new situation. Therefore, more attention is being paid to studying the intention to use technology; in other words, the degree to which a teacher is willing to use technology [5], or the degree to which a teacher would like to use technology in the future [6].

Although Estonia is widely known as a successful digitally developed country, and despite the fact that our teachers' technology skills are generally good [7] and several schools have conducted e-learning days [8], teachers were still confused and faced trouble during the distance learning period in spring 2020 [9]. Teacher education must prepare 
future teachers so that they have the positive ability and desire to integrate technology into their teaching, because otherwise, it will be impossible for teachers to manage the demands of modern education. However, it has been found that the new generation of teachers is also struggling, and unfortunately, student teachers are often insufficiently prepared for integrating technology [10]. The preparation of student teachers is also important because the experience and practice in using technology gained during teacher education has influenced their subsequent use of technology [11].

It is important, in the preparation of student teachers, to understand what influences their intention to use technology. In addition to knowledge and skills, researchers (e.g., $[12,13])$ have also emphasized the important role of beliefs in whether and how teachers will use the possibilities of technology in their work. With this knowledge about the factors that influence the intention to use technology, we can plan teacher education curricula not only to help teachers acquire the necessary skills, but also to help shape their attitudes and beliefs.

The integration of technology into teaching is complex and influenced by different factors [14]. It is influenced on the one hand by external factors, such as the availability of technical resources and support, and on the other hand by internal factors, such as knowledge, skills, beliefs, and attitudes. To change technology use among teachers, Ertmer and Ottenbreit-Leftwich [15] highlighted in their literature review four variables of teacher change: knowledge, beliefs and attitudes, self-efficacy, and school culture. Therefore, the use of technology in teaching is influenced primarily by objective factors, the teacher's professional knowledge and skills, and secondarily by their subjective beliefs and attitudes [16]. The integration of technology by teachers can be affected by various barriers, which can also be divided into external factors (e.g., time, support, resources) that are outside the teacher's control and internal factors (knowledge, self-efficacy, beliefs, and attitudes). The latter can be controlled and changed [17,18], although it is difficult to change beliefs and attitudes [19].

Teacher education should focus on influencing internal factors. If teachers have strong enough beliefs and knowledge, they will overcome the barriers to integrating technology into their teaching $[15,18]$.

\subsection{Knowledge and Skills}

The conception of professional knowledge needed for teachers has changed over time from a focus purely on content knowledge [20]. Areas of knowledge among teachers have also been seen as either separate and independent areas [21,22] or as integrated [20]. To use technology, knowledge about technology is important in addition to content and pedagogical knowledge. Hence, Mishra and Koehler [23] developed the TPACK model consisting of seven parts. The conceptual knowledge that goes into integrating technology could be viewed as a combination of three components of this model: technological pedagogical knowledge (TPK), technological content knowledge (TCK), and technological pedagogical and content knowledge (TPACK) [24]. However, the relationship between TPACK and technology integration has not been fully understood [25].

In some cases, it is difficult to determine the distinction between knowledge and beliefs [13]. Instruments used to measure knowledge are, in many instances, self-reporting scales [25,26], or interviews (e.g., [20]) that do not measure real knowledge, but perceptions about knowledge, which might also be viewed as beliefs. Several studies have found relationships between knowledge or perceived knowledge and beliefs. It has been reported that perceived TPACK knowledge is positively related to self-efficacy for integrating technology [27] and the intention to integrate technology into teaching [28,29]. Studies have also found that attitudes towards technology were related to TPACK knowledge and the skills of student teachers via a two-way effect-positive attitudes were associated with higher evaluations of TPACK competencies and vice versa [25]. At the same time, beliefs play an important role in the acquisition of knowledge [13], and it has been found that teachers and attitudes influence knowledge [14]. 


\subsection{Beliefs and Attitudes}

Besides knowledge, beliefs and attitudes are also important for influencing teachers' behaviour and decisions [13] because beliefs and attitudes as internal factors could be controlled and changed [18]. However, Rienties et al. [30] have found that university professional development courses for teachers increased their knowledge. Still, after delivering pure knowledge, beliefs remained unchanged, so those authors concluded that changing the attitudes and beliefs of senior teachers is a difficult and long process. In addition to the curricula, teacher educators and mentor teachers are also very important in teacher education, as they act as important role models for future teachers in terms of technology integration [26]. Therefore, more attention needs to be paid to student teachers' beliefs and attitudes in teacher education curricula.

Regarding technology integration, the two most commonly mentioned beliefs are perceived usefulness and perceived ease of use [5,31-33]. Perceived usefulness could be defined as the degree to which a teacher believes that using technology would help them to improve performance. Perceived ease of use is explained as the degree to which a teacher believes that using technology would be free of effort, that technology can be integrated into teaching without particular difficulty $[5,31]$.

Attitudes are formed by beliefs [13], meaning that an attitude can be based on the overall evaluation of different beliefs [26]. Attitude toward technology use (ATU) is defined as teachers' willingness to use technology in the classroom [26] or the degree of positive feelings about the use of technology [31]. Attitude toward technology use has also often been discussed in studies as influencing the intention to use technology [31-33].

Several models have been developed to study the influence of beliefs and attitudes about the intention in teachers and student teachers to use technology [34]. Probably the most common is the technology acceptance model (TAM) elaborated by Davis [35], which was then modified by Davis and colleagues [5]. In this model [5], the beliefs of perceived usefulness and perceived ease of use influence attitude toward use. In addition, perceived ease of use influences perceived usefulness, and perceived usefulness in turn along with attitude toward use directly influence intention to use. The TAM model has been used in several studies $[6,28,33,36]$ and in different cultural settings (e.g., [32]). However, not all studies have confirmed the TAM model. For example, in some studies $[13,28]$, a direct effect of perceived ease of use on intention to use was not found. In addition, the results of one study [36] confirmed neither the hypothesis that perceived ease of use has a direct effect on attitude toward use nor the hypothesis that attitudes in turn to the intention to use technology.

Earlier studies have found different results about the relationships between beliefs, attitudes, and the intention to use technology in teaching. In the case of student teachers in Singapore and Malaysia, perceived usefulness of technology, ease of use, and attitude toward computer use were found to be key determinants of behavioural intention toward technology use [32]. More specifically, some studies have found that intention to use is directly affected by perceived usefulness $[31,33,36]$ and attitude toward use $[31,33]$. In contrast, it has been found that attitude does not affect intention to use [36]. Furthermore, the role of perceived ease of use is not clear. In some studies, perceived ease of use had an indirect impact on intention to use via perceived usefulness [31,36] and attitudes [31]. However, the results of another study [36] indicate that perceived ease of use did not affect attitude toward use. In addition, it was found in $[31,33]$ that attitudes influenced intention to use, but such an effect was not found in [36].

In general, these beliefs and attitudes have been found to impact the use of technology in teaching $[15,37,38]$. Therefore, it is very important to focus on the use of technology in teacher education in order to support positive attitudes and form an understanding that the use of technology is valuable in teaching, useful for both teachers and students, and easy. 


\subsection{Behavioural Intention to Use Technology in Education in Relation to Knowledge, Beliefs, and Attitudes}

Previously, we discussed research wherein the effects of either the teacher's knowledge and skills or beliefs and attitudes on the intention to use technology were studied separately. There have been quite a few studies that combined teacher knowledge and skills as well as beliefs and attitudes and studied how these all affected the intention to use technology in teaching - with samples of Korean [6], Serbian [29], and Chinese student teachers [28]. At the same time, a study with a sample of Turkish student teachers [14] studied how the use of ICT and attitudes toward technology predicted TPACK knowledge. Farjon et al. also presented an interesting study [10] wherein the integration of technology by student teachers was explained using the WEST model, which combines will, experience, skills, and tools. In that study, attitudes and beliefs (= will) were found to have the strongest impact on technology integration.

Both factors-attitudes towards the use of technology in education and teachers' knowledge-are critical to the integration of technology. Several studies have addressed these aspects, but the relationships between them have not been fully understood [25] Furthermore, along with teacher beliefs, teacher readiness has also shown a positive direct effect on technology integration [39].

Earlier studies have found different results about the relationship between beliefs, attitudes, and knowledge. In the case of teachers [39], it was found that their technology integration practices have influenced directly by knowledge and beliefs (including selfefficacy). More specifically, slightly contradictory results can be pointed out. While some studies $[28,29]$ found that the intention to use technology was directly affected by TPACK knowledge, results from one study [6] showed that TPACK knowledge did not have a direct impact on intention to use, but influenced it indirectly through teacher self-efficacy, ease of use, and perceived usefulness. The latter three all directly affected the intention to use.

Different results have also been obtained using models regarding the effect of beliefs on the intention to use technology. The strongest effect of perceived usefulness on the intention to use was found in $[6,16]$. In contrast, other studies claimed that there was no significant effect between perceived usefulness and intention to use [29] and that the intention to use was influenced directly by perceived usefulness and attitude toward use, but indirectly by ease of use, the impact of which was mediated by perceived usefulness and attitudes [28].

\subsection{The Aim, Research Questions, and Hypotheses}

As previous studies have found, in the preparation of teachers, attention must be paid to knowledge and skills as well as to the formation of positive attitudes and beliefs about the usefulness of technology [29]. However, the factors influencing intention to use technology and the relationships between these factors have not yet been sufficiently studied (e.g., $[18,25])$, and the results are contradictory. Therefore, the aim of this study was to identify the impact of perceived knowledge about technology integration, beliefs about using technology, and attitude towards use on intention to use technology among student teachers.

Among preservice teachers, studies have assessed the effect of professional knowledge on intention solely to use (e.g., [14]) and how beliefs affect intention to use (e.g., [33]). A few studies $[6,28,29]$ estimated a model that included three dimensions: knowledge, beliefs, and attitudes. The present study focused on perceived knowledge about technology integration and on beliefs about using technology (perceived ease of use and perceived usefulness) from the TAM model, attitude toward using technology in education, and intention to use technology in education. Going beyond the previous studies, we also separately analysed perceived usefulness for students and perceived usefulness for teachers. According to the hypothesized model (Figure 1), we formulated four research questions and eleven hypotheses. 


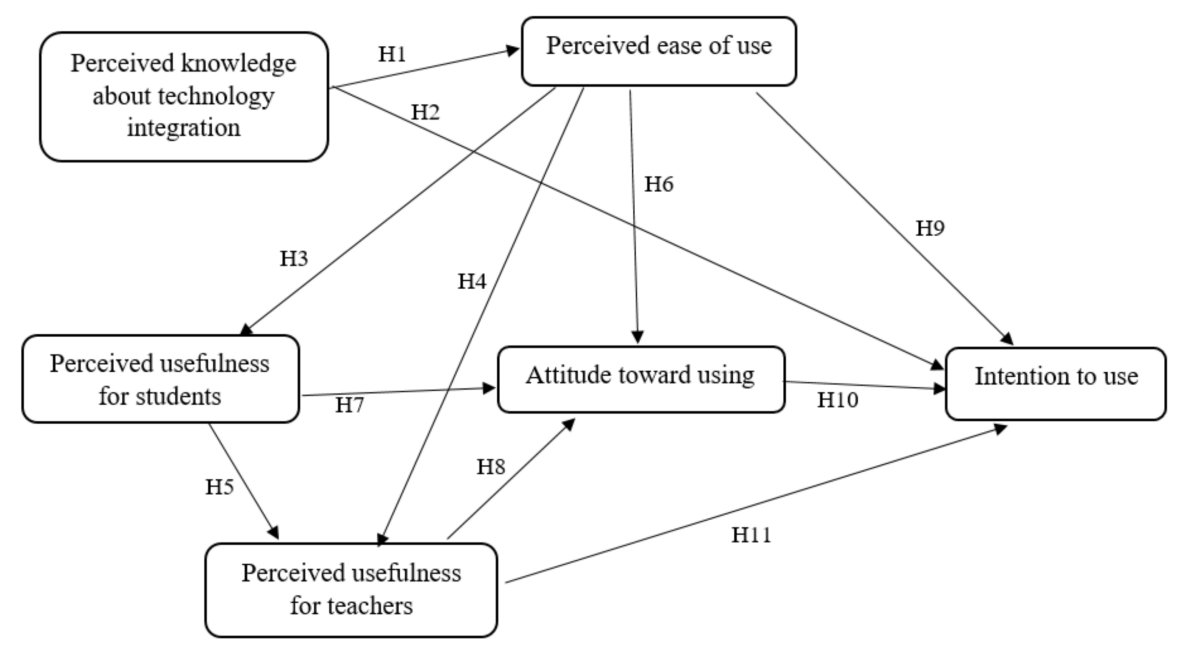

Figure 1. Hypothesized model.

The results concerning the influence of perceived knowledge about technology integration on perceived ease of use in the models evaluating the effect on intention to use have to date been contradictory. One previous study [6] proved that perceived knowledge about technology integration positively influenced student teachers' perceived ease of using technology, but [28] did not support such a link. The results about the influence of TPACK on intention to use are also mixed. A positive significant effect between these constructs in the case of student teachers was found in some studies (e.g., [28,29]), but [6] found that TPACK did not directly affect student teachers' intention to use technology. However, Pajares [13] pointed out that knowledge, not beliefs, influences teachers' decision-making, and therefore, our first research question was about the influence of perceived knowledge about technology integration.

Research question 1 (RQ1): How does the perceived knowledge about technology integration in student teachers influence their perceived ease of use and intention to use technology in education?

Hypothesis 1 (H1). Student teachers' perceived knowledge about technology integration has a positive effect on their perceived ease of use.

Hypothesis 2 (H2). Student teachers' perceived knowledge about technology integration has a positive effect on their intention to use.

According to the TAM model [5], perceived ease of use influences perceived usefulness. This direct effect was also confirmed by several previous studies (e.g., $[6,28,33,36])$. However, the effect on the two separate dimensions of perceived usefulness (perceived usefulness for teachers and for students) and the link between these two separate influences has not been previously studied. Therefore, our second research question was about the links between the perceived ease of use and perceived usefulness for teachers and students.

Research question 2 (RQ2): How does student teachers' perceived ease of use influence their perceived usefulness, and how are perceived usefulness for students and for teachers related?

Hypothesis 3 (H3). Student teachers' perceived ease of use has a positive effect on their perceived usefulness for students.

Hypothesis 4 (H4). Student teachers' perceived ease of use has a positive effect on their perceived usefulness for teachers. 
Hypothesis 5 (H5). Student teachers' perceived usefulness for students has a positive effect on their perceived usefulness for teachers.

The TAM model [5] states that two specific beliefs, perceived usefulness and perceived ease of use, influence a person's attitude toward using technology. This model was confirmed empirically using a sample of student teachers in Singapore and Malaysia [32]. In our study, we separated perceived usefulness for teachers and perceived usefulness for students, and therefore, the third research question was about how three specific beliefsperceived ease of use, perceived usefulness for students, and perceived usefulness for teachers-influenced student teachers' attitude toward using technology.

Research question 3 (RQ3): How do student teachers' beliefs about using technology influence their attitude toward using technology in education?

Hypothesis 6 (H6). Student teachers' perceived ease of use has a positive effect on their attitude toward using technology in education.

Hypothesis 7 (H7). Student teachers' perceived usefulness of technology for students has a positive effect on their attitude toward using technology in education.

Hypothesis 8 (H8). Student teachers' perceived usefulness of technology for teachers has a positive effect on their attitude toward using technology in education.

According to the TAM model [5], perceived usefulness and attitude toward use have a direct effect on intention to use. These two constructs, together with perceived ease of use, were identified as key determinants of behavioural intention [32]. Perceived ease of use and perceived usefulness as influencers of the intention to use have also been reported by several studies (e.g., [6,16,33]). However, in a study by Teo [31], only the direct effects of perceived usefulness and attitude toward use were confirmed, and perceived ease of use only influenced intention to use indirectly through these two constructs. The indirect influence of perceived ease of use mediated by perceived usefulness was also reported by Mei et al. [28]. Our last research question was about the two specific beliefs and attitude toward using technology that influence student teachers' intention to use technology in education.

Research question 4 (RQ4): How do student teachers' beliefs about using technology and attitude toward using technology in education influence their intention to use technology in education?

Hypothesis 9 (H9). Student teachers' perceived ease of use has a positive effect on their intention to use technology.

Hypothesis 10 (H10). Student teachers' attitude toward using technology in education have a positive effect on their intention to use technology.

Hypothesis 11 (H11). Student teachers' perceived usefulness for teachers has a positive effect on their intention to use technology.

\section{Materials and Methods}

\subsection{Sample}

The sample consisted of 232 student teachers from the University of Tartu. In our sample, $205(88 \%)$ were female student teachers, which corresponds to the general data on teachers (2020) in Estonia, where it is reported that $86 \%$ of teachers are female. Of the respondents, $103(44 \%)$ studied at the bachelor level and $129(56 \%)$ at the master's level. The average age of the respondents was $31.8(\mathrm{SD}=10.44)$. Almost half of the participants in our sample (108) had teaching experience, with the average length being $3.0(\mathrm{SD}=6.05)$ 
years. According to the TALIS survey [7], beginning teachers are on average 36 years old, and in Estonia, several student teachers, before studying or at the same time of their studies, already work in schools as teachers with temporary contracts.

\subsection{Data Collection}

A questionnaire consisting of two parts and using a 5-point Likert-type scale (1strongly disagree, 2-disagree, 3-neither agree nor disagree, 4-agree, and 5-strongly agree) was used in this study. The first part of the questionnaire measured perceived professional knowledge according to the TPACK framework and consisted of 32 items. Based on confirmatory factor analysis (CFA), items in seven theoretical constructs were divided between four factors: Technology, Pedagogy, Content, and Technology integration [40]. Only the latter factor, perceived knowledge about technology integration (Cronbach's alpha 0.95), consisting of the 13 items describing the TPK, TCK, and TPACK areas, was included in this study, as according to Koehler and Mishra [24], these three components of the model are essential for integrating technology in the teaching process.

The second part of the questionnaire consisted of 21 items and was based on the TAM model. The items measured five constructs:

- $\quad$ nine items for describing perceived usefulness (e.g., using technology enhances my effectiveness; using technology improves cooperation between the learners);

- $\quad$ four items measuring perceived ease of use (e.g., I find computers easy to use; computer icons are easy to understand for me);

- four items describing attitude toward using technology in education (e.g., technology is valuable in teaching; every teacher must be able to use technology); and

- four items measuring intention to use (e.g., I intend to allow learners to use the technology to explore different topics; I intend to guide students to use the Internet to communicate with experts or other learners to enrich their learning experiences).

The items for the questionnaire were selected based on previous studies $[5,16,33,36]$. As the first step of this study, this scale was validated.

At the end of the questionnaire, we asked for information about the respondents background. The questionnaire ended with statements about agreement to using the collected data in research.

In October 2019, all student teachers participating in the basic pedagogy course 'Learning and Instruction Design' received a link to the questionnaire. Respondents were provided with an informed consent form explaining the purpose of the study, the voluntary nature of the study, and the option to quit at any time. This study was not related to the course assessment, and personal data was not collected.

\subsection{Data Analysis}

Data analysis was conducted using IBM SPSS Statistics version 26.0 and IBM SPSS Amos version 26.0. In the first step, the TAM scale was validated. First, an exploratory factor analysis (EFA) using Kaiser normalization and the robust maximum likelihood method with varimax rotation was performed. The Kaiser-Meyer-Olkin measure of sampling adequacy $(\mathrm{KMO}=0.909)$ and Bartlett's test of sphericity $\left(\chi^{2}=3252.722, \mathrm{df}=231\right.$, $p<0.001$ ) showed that the data were factorable. All communalities were at least 0.60 , and the Kaiser-Guttman rule indicated that the structure of the five-factor model was suitable. The model described $71.15 \%$ of the total variance. This five-factor model was estimated using a CFA, and robust estimation was used.

Mean factor scores for six constructs (five from the TAM scale and Perceived knowledge about technology integration from the TPACK scale) were calculated as means of the items belonging to each factor.

For testing the hypotheses, path analysis, as a special type of structural equation modelling (SEM), was used. This particular analysis method was used because it allows simultaneous testing of the magnitude and the significance of the complex predictive 
relationships between a set of variables. The maximum likelihood estimation (MLE) method was used.

To analyse the goodness of fit of the CFA and path analysis, at first, the chi-square $\left(\chi^{2}\right)$ test indicating absolute/predictive fit was used. According to Schreiber and colleagues [41] an SEM model fits the data well when the $p$-value associated with the $\chi^{2}$ test is nonsignificant. As recommended by Kline [42], the chi-squared per degree of freedom was also calculated. As the $\chi^{2}$ test is quite sensitive to sample size, the use of relative goodness-of-fit indices is also strongly recommended in the case of large sample sizes [43]. Therefore, the models were evaluated according to two comparative indices: the comparative fit index (CFI), and as our sample was over 200, the normed fit index (NFI). The standardized root mean square residual (SRMR) was used as an absolute fit index, and as parsimony correction indices we used the root mean square error of approximation (RMSEA) suggested by Brown [44]. The cutoff points used in this study were: the $\chi^{2}$ test is nonsignificant, the ratio of $\chi^{2}$ to $\mathrm{df}$ is 2 or less [41], the CFI values are over 0.95 [45], the NFI values are over 0.90 [43], the RMSEA values are close to 0.06 [45], and SRMR is below $0.08[41,45]$.

\section{Results}

\subsection{Factor Structure of the Second Part of the Questionnaire}

As the first step, confirmatory factor analysis was performed to estimate the factor structure of the scale. The exploratory factor analysis (EFA) reached a five-factor model consisting of perceived usefulness for teachers, perceived usefulness for students, perceived ease of use, attitude toward using technology, and intention to use technology. Internal reliabilities (Cronbach's alpha) for the factors were 0.874 for perceived usefulness for teachers, 0.840 for perceived usefulness for students, 0.890 for perceived ease of use, 0.848 for attitude toward use, and 0.855 for intention to use.

This five-factor model was estimated using a confirmatory factor analysis. The first model showed lack of fit: $\chi^{2}=397.876, \chi^{2} / \mathrm{df}=2.223, \mathrm{CFI}=0.925$, TLI $=0.912$, RM$\mathrm{SEA}=0.073, \mathrm{SRMR}=0.060$. After taking into account several modification indices, the final model with 21 items showed acceptable fit with: $\chi^{2}=289.283, \chi^{2} / \mathrm{df}=1.732, \mathrm{CFI}=0.958$, $\mathrm{TLI}=0.947, \mathrm{RMSEA}=0.056, \mathrm{SRMR}=0.048$. The standardized factor loadings (ranging from 0.61 to 0.92 ) and item reliabilities (ranging from 0.38 to 0.85 ) were also moderate or high, suggesting that all the items seem to be good indicators of the latent factors. The model consisted of five factors:

- $\quad$ perceived usefulness for teachers (PUT), consisting of four items with the standardized factor loadings ranging from 0.752 to 0.920 (item reliabilities from 0.565 to 0.847 );

- perceived usefulness for students (PUS), consisting of five items and the standardized factor loadings ranging from 0.614 to 0.826 (item reliabilities from 0.377 to 0.683 );

- perceived ease of use (PEU), consisting of four items with the standardized factor loadings ranging from 0.759 to 0.847 (item reliabilities from 0.577 to 0.763 );

- attitude toward using technology (ATU), consisting of four items and the standardized factor loadings ranging from 0.690 to 0.826 (item reliabilities from 0.476 to 0.682 ); and - intention to use technology (IU), consisting of four items with the standardized factor loadings ranging from 0.619 to 0.888 (item reliabilities from 0.384 to 0.788 ).

The composite reliabilities (CR) of all factors were above 0.07 (see Table 1).

Convergent validity was evaluated by examining the average variance extracted (AVE), which was recommended by Hair et al. [46] to be greater than 0.5. In our model, only in the case of Perceived usefulness for students was AVE less than 0.5, but as emphasized by Fornell and Larcker [47], when AVE is less than 0.5 but the composite reliability is higher than 0.6 , the convergent validity of the construct is still adequate, as in our case.

To evaluate discriminant validity, the heterotrait-monotrait (HTMT) criterion suggested by Henseler and colleagues [48] was used. Table 1 also presents the values of the HTMT ratios of the correlations. Using a threshold of 0.85 suggested by Voorhees et al. [49], the discriminant validity of the scale was also established. 
Table 1. Convergent and discriminant validity.

\begin{tabular}{cccccccc}
\hline \multirow{2}{*}{ Factor } & \multirow{2}{*}{ CR } & AVE & \multicolumn{5}{c}{ HTMT Analysis } \\
\cline { 5 - 8 } & & & PUT & PUS & PEU & ATU & IU \\
\hline PUT & 0.878 & 0.644 & & & & & \\
PUS & 0.830 & 0.496 & 0.659 & & & & \\
PEU & 0.879 & 0.644 & 0.530 & 0.409 & & \\
ATU & 0.852 & 0.591 & 0.618 & 0.837 & 0.293 & & \\
IU & 0.818 & 0.534 & 0.527 & 0.673 & 0.362 & 0.819 & \\
\hline
\end{tabular}

Note: PUT = perceived usefulness for teachers; PUS = perceived usefulness for students; PEU = perceived ease of use; ATU = attitude toward using technology; IU = intention to use technology.

\subsection{Model to Predict Intention to Use Technology}

Path analysis was used to estimate the model's ability to predict the intention to use technology by student teachers. The standardized regression coefficient for intention to use technology $\mathrm{R}^{2}$ was 0.51 , indicating that this model could explain $51 \%$ of the variance in intention to use technology.

Of the eleven path coefficients, eight were statistically significant (see Table 2).

Table 2. Results from testing the hypotheses with parameter estimates.

\begin{tabular}{ccccc}
\hline Hypotheses & Path & Path Coefficient & $\boldsymbol{t}$ & $\boldsymbol{p}$-Value \\
\hline H1 & TPACK $\rightarrow$ PEU & 0.669 & 13.673 & $<0.001$ \\
H2 & TPACK $\rightarrow$ IU & -0.003 & -0.050 & 0.960 \\
H3 & PEU $\rightarrow$ PUS & 0.364 & 5.934 & $<0.001$ \\
H4 & PEU $\rightarrow$ PUT & 0.297 & 5.400 & $<0.001$ \\
H5 & PUS $\rightarrow$ PUT & 0.452 & 8.210 & $<0.001$ \\
H6 & PEU $\rightarrow$ ATU & -0.047 & -0.910 & 0.363 \\
H7 & PUS $\rightarrow$ ATU & 0.593 & 10.649 & $<0.001$ \\
H8 & PUT $\rightarrow$ ATU & 0.220 & 3.769 & $<0.001$ \\
H9 & PEU $\rightarrow$ IU & 0.135 & 2.020 & 0.043 \\
H10 & ATU $\rightarrow$ IU & 0.629 & 11.536 & $<0.001$ \\
H11 & PUT $\rightarrow$ IU & 0.059 & 0.989 & 0.323 \\
\hline
\end{tabular}

Note: TPACK = perceived knowledge about technology integration; PEU = perceived ease of use; PUS = perceived usefulness for students; PUT = perceived usefulness for teachers; ATU = attitude toward using technology; $\mathrm{IU}=$ intention to use technology.

Perceived knowledge about technology integration directly influenced perceived ease of use, but influenced intention to use only indirectly $(\beta=0.205, p<0.05)$. Perceived ease of use had a direct significant effect on perceived usefulness for students and perceived usefulness for teachers. Perceived usefulness for students influenced perceived usefulness for teachers. Both beliefs about usefulness (perceived usefulness for students and perceived usefulness for teachers) had significant positive effects on attitude toward using technology. However, perceived ease of use had only indirect effects on attitude toward using technology $(\beta=0.294, p<0.05)$. Perceived ease of use and attitude toward using technology had significant direct effects on intention to use technology, but perceived usefulness for teachers influences intention to use technology only indirectly $(\beta=0.149, p<0.05)$. In addition, the indirect effect of perceived usefulness for students was statistically significant ( $\beta=0.502, p<0.06)$. Because perceived ease of use has both a significant direct and indirect effect on intention to use $(\beta=0.185, p<0.05)$, the total effect of perceived ease of use on intention to use is also significant $(\beta=0.311, p<0.05)$. Estimates of the path coefficients with the results of significance testing are presented in Figure 2. 


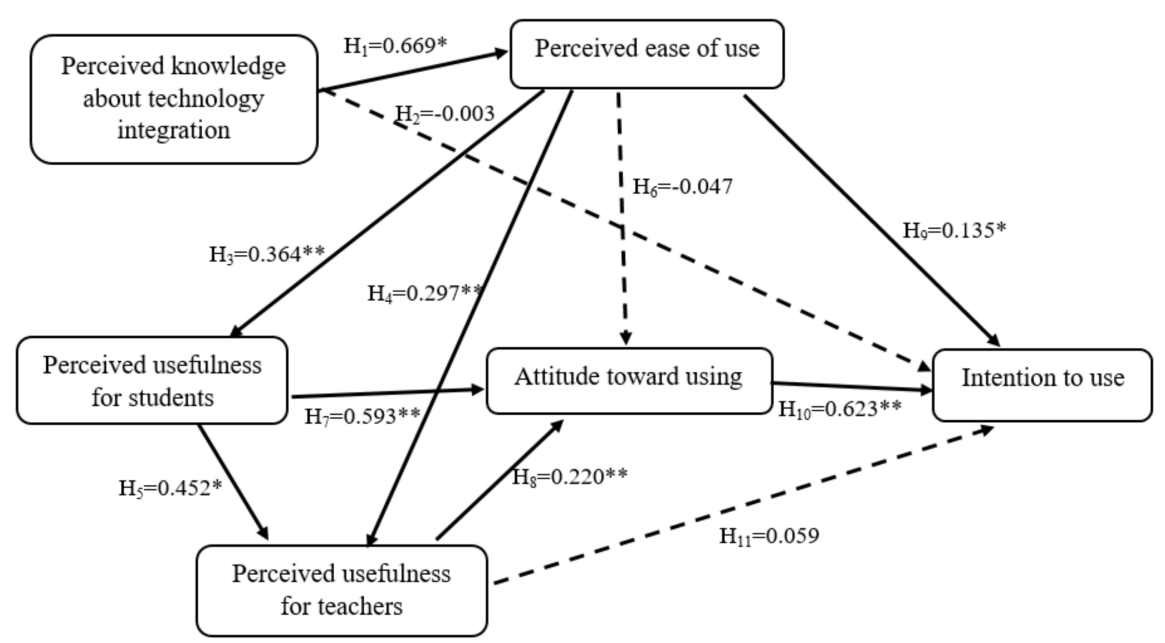

Figure 2. Path analysis of the proposed research model with standardized path coefficients. Note: The bold lines represent the significant path coefficients and the broken lines insignificant. ${ }^{*} p<0.05$; ** $p<0.001$.

\section{Discussion}

The aim of this study was to identify the impact of perceived knowledge about technology integration, beliefs about using technology and attitude toward using on intention to use technology among first-year student teachers and teachers. Our model consisted of six constructs: perceived knowledge about technology integration (validated in a previous study [45], perceived ease of use, perceived usefulness for students, perceived usefulness for teachers, attitude toward using technology in education, and intention to use technology in education. The first step was to validate the scale measuring beliefs and intention to use technology.

The results from the confirmatory factor analysis confirmed that the scale consisted of five factors. According to the TAM model, the factors that emerged included perceived ease of use, attitude toward using technology, and intention to use technology. The factor in the TAM model describing perceived usefulness was split into two factors, perceived usefulness for teachers and perceived usefulness for students, which was not reported previously. Previous studies about the TAM model and beliefs about technology use in education used only one perceived usefulness factor, despite the fact that in some studies (e.g., $[4,16,39])$, this factor included items describing both usefulness for students and usefulness for teachers. The convergent and discriminant validity of the scale were also established, indicating that separating perceived usefulness into two factors is reasonable.

Our hypothetical model predicting intention to use was proven to be applicable and could explain $51 \%$ of the variance in intention to use technology. The $p$-value was greater than 0.05 , and the model showed sufficient fit indices in the path analysis [41]. Eleven hypotheses were posed, and eight of these were confirmed. We now discuss the results according to the research questions.

Answering our first research question, we found that perceived knowledge about technology integration in student teachers had a significant direct influence on their perceived ease of use, which is in line with one previous study [6], but contrary to other findings [28]. However, concerning the influence of perceived knowledge about technology integration on intention to use, our results did not support previous studies $[28,29]$ and indicated only a significant indirect influence mediated by perceived ease of use. In addition, the previous model [6] did not confirm the direct influence of TPACK on the intention to use. The results of our study demonstrated that student teachers who perceived their knowledge about technology integration to be higher were more likely to have increased perception of ease of use in regard to technology. Nevertheless, knowledge about technology integration seems not to be sufficient to influence the intention to use technology in education; student 
teachers should also perceive that using technology is easy for them, and this requires practice, not only knowledge.

Our second research question asked how the perceived ease of use in student teachers influences their perceived usefulness and how perceived usefulness for students and for teachers are related. All three hypotheses posed under this research question were confirmed. Our results indicated that perceived ease of use had a significant positive influence on both constructs describing perceived usefulness (perceived usefulness for teachers and perceived usefulness for students). In addition, perceived usefulness in the TAM model [5] is treated as one construct, and several previous studies (e.g., [6,28,33,36]) confirmed that perceived ease of use positively influenced perceived usefulness. However, the CFA analysis in our study indicated that perceived usefulness could be seen as a two-dimensional construct (perceived usefulness for students and perceived usefulness for teachers), and these results went beyond previous reports in indicating that perceived ease of use influenced both dimensions of perceived usefulness positively. Perceiving using technology as easy to use likely increases student teachers' positive belief that technology in education is useful both for students and teachers. A further novel finding was that perceived usefulness for students had a significant effect on perceived usefulness for teachers, which also indicated that these two constructs were closely related.

Regarding the third research question, on how perceived ease of use and perceived usefulness of technology among student teachers influence their attitude toward using technology in education, we also evaluated three hypotheses, two of which were supported. Our results showed that both perceived usefulness for teachers and perceived usefulness for students significantly influenced student teachers' attitude toward using technology in education. That is, if student teachers perceive that technology is helpful for students and for teachers, it might increase their positive attitude towards using technology in education. In the TAM model [5], ease of use was also linked to the attitude, but interestingly, our results did not confirm that perceived ease of use had a significant effect on attitude toward using technology. Our study confirmed the results of [36]. However, another study [32] demonstrated that perceived ease of use also had a positive effect on attitude toward using. In our study, on the other hand, the influence of perceived ease of use on attitude toward using technology was indirect and mediated by perceived usefulness for teachers and perceived usefulness for students. The reason why our study did not prove a direct influence by perceived ease of use on attitude toward using technology might be that the technology is now more widely spread in education than before. There are plenty of technologies that are easy to use, and therefore, perceived ease of use by itself does not influence attitude. Technology that is perceived as easy to use must also be perceived as useful before it positively affects the attitude toward use.

Our last research question was about how student teachers' beliefs and attitudes toward using technology influence their intention to use it. Three hypotheses were included in this research question, and two of these were confirmed. Our results demonstrated that both perceived ease of use and attitude toward using technology in education had significant positive effects on the intention to use technology in education. In other words, if student teachers perceive that using technology is easy and their attitudes toward using technology in education are more positive, this will likely increase their intention to use technology in education. Only in one previous study [32] was the direct effect of all these three constructs (perceived ease of use, perceived usefulness, and attitude toward using technology) on intention to use technology proven. Several previous studies demonstrated that perceived ease of use together with perceived usefulness were determinants of the intention to use (e.g., $[6,16,33]$ ) or that only perceived usefulness had a direct effect, as perceived ease of use was mediated by perceived usefulness $[28,31]$. Therefore, it was surprising that in our study, perceived usefulness for teachers had no significant influence on intention to use. Both perceived usefulness for teachers and perceived usefulness for students had significant indirect effects on intention to use mediated by the attitude toward using technology, indicating that perceived usefulness for teachers alone did not lead 
to the intention to use. According to these results, to affect intention to use, perceived usefulness for teachers needs first to affect attitude. However, previous studies $[28,31,33]$ and the TAM model itself [5] demonstrated a direct influence of perceived usefulness on behavioural intention. One explanation why perceived usefulness for teachers had only an indirect influence through attitude in our study might be that we split perceived usefulness into perceived usefulness for teachers and for students. In this model, we estimated only the influence of perceived usefulness for teachers on the intention to use. However, the intention to use might also depend on how useful technology is perceived for students. Therefore, the relationships between different aspects of perceived usefulness and intention to use need to be studied further.

\section{Conclusions}

In conclusion, our study demonstrated that student teachers' perceived ease of use and attitude toward using technology in education were the main constructs influencing their intention to use technology in education, having direct effects, but also being mediators. Nevertheless, perceived knowledge about technology integration and perceived usefulness for teachers and for students also seemed to be important, as knowledge influenced perceived ease of use, and both constructs of perceived usefulness influenced attitude toward using technology in education (and through this also influenced intention to use technology in education).

The novelty of this study lies in the finding that perceived usefulness was split into two factors: perceived usefulness for teachers and perceived usefulness for students. As it is important that teachers also think about how useful a given technology is for learners, we suggest using these separate constructs in further research.

The model was also novel, indicating that the perceived usefulness might not be a crucial factor of intention to use, as it was found in previous studies, and may have a purely indirect effect. Based on the result that perceived ease of use was one of the key determinants of intention to use technology in education, it is important that teacher educators not only talk about how easy it is to use technology in the teaching process, but also have good technological skills themselves to demonstrate the ease of using technology and by being role models for student teachers. At the same time, it is important to give students the opportunity to use the technology themselves in their studies so that use becomes easy for them. However, it is essential to provide good technological knowledge in addition to demonstrating the usefulness of technology.

This study also had several limitations that must be taken into account. The scale used involved a self-assessment instrument, and the respondents could under- or overestimate their responses. Our sample also consisted of student teachers from one university, which might limit the generalization of the results. The TAM model [5] includes external variables, from which we only used perceived knowledge about technology integration; however, other aspects such as subjective norms or pedagogical beliefs could also have an influence. In future studies, it would be useful to test this model among in-service teachers and in other countries.

Author Contributions: Conceptualization, P.L. and M.T.; methodology, P.L.; validation, P.L.; formal analysis, P.L.; investigation, P.L. and M.T.; resources, P.L. and M.T.; data curation, P.L. and M.T.; writing-original draft preparation, P.L. and M.T.; writing-review and editing, P.L. and M.T.; visualization, P.L. All authors have read and agreed to the published version of the manuscript.

Funding: This research received no external funding.

Institutional Review Board Statement: The research is in line with the personal data management (2019) developed by the Republic of Estonia Data Protection Inspectorate and The European Code of Conduct for Research Integrity (2020) by All European Academies. Ethical review and approval were waived for this study, because no specific evaluation at the Faculty of Educational Sciences is needed for the type of research that is introduced in the manuscript, which aims to improve teacher education curricula. 
Informed Consent Statement: Informed consent was obtained from all course participants involved in the study.

Data Availability Statement: Data is available from the corresponding author on request.

Conflicts of Interest: The authors declare no conflict of interest.

\section{References}

1. Estonian Lifelong Learning Strategy 2020. 2014. Available online: https://www.hm.ee/sites/default/files/estonian_lifelong_ strategy.pdf (accessed on 10 March 2021).

2. Education Strategy 2021-2035. 2020. Available online: https://www.hm.ee/sites/default/files/eesti_haridusvaldkonna_ arengukava_2035_seisuga_2020.03.27.pdf (accessed on 10 March 2021).

3. Ottenbreit-Leftwich, A.T.; Glazewski, K.D.; Newby, T.J.; Ertmer, P.A. Teacher value beliefs associated with using technology: Addressing professional and student needs. Comput. Educ. 2010, 55, 1321-1335. [CrossRef]

4. Hol, D.; Aydın, I. Is technology in our classrooms? EFL teachers' beliefs and engagement with technology in the classroom. J. Educ. Issues 2020, 6, 38-58. [CrossRef]

5. Davis, F.D.; Bagozzi, R.P.; Warshaw, P.R. User acceptance of computer technology: A comparison of two theoretical models. Manag. Sci. 1989, 35, 982-1003. [CrossRef]

6. Joo, Y.J.; Park, S.; Lim, E. Factors influencing preservice teachers' intention to use technology: TPACK, teacher self-efficacy, and technology acceptance model. J. Educ. Technol. Soc. 2018, 21, 48-59.

7. Taimalu, M.; Uibu, K.; Luik, P.; Leijen, Ä. Õpetajad ja koolijuhid elukestvate õppijatena. OECD Rahvusvahelise Õpetamise ja Õppimise Uuringu TALIS 2018 uuringu tulemused, 1. osa. [Teachers and School Leaders as Lifelong Learners. The OECD International Study on Teaching and Learning TALIS 2018 Results, Volume I. Estonian Report]. 2019. Available online: https: / / www.hm.ee/sites/default/files/talis_eesti_raporti_i_osa.pdf (accessed on 10 January 2021).

8. Kori, K.; Beldman, P.; Tõnisson, E.; Luik, P.; Suviste, R.; Siiman, L.; Pedaste, M. IT Oskuste Arendamine Eesti Koolides. Uuringu Raport. [Development of IT Skills in Estonian Schools. Study Report]. 2019. Available online: https://transferwise.com/ documents /IT\%20oskuste\%20arendamine\%20Eesti\%20koolides.pdf (accessed on 8 January 2021).

9. Luik, P.; Lepp, M. Local and external stakeholders affecting educational change during the coronavirus pandemic: A study of Facebook messages in Estonia. Educ. Sci. 2021, 11, 113. [CrossRef]

10. Farjon, D.; Smits, A.; Voogt, J. Technology integration of pre-service teachers explained by attitudes and beliefs, competency, access, and experience. Comput. Educ. 2019, 130, 81-93. [CrossRef]

11. Tondeur, J.; Roblin, N.P.; van Braak, J.; Voogt, J.; Prestridge, S. Preparing beginning teachers for technology integration in education: Ready for take-off? Technol. Pedagog. Educ. 2017, 26, 157-177. [CrossRef]

12. Miranda, H.P.; Russell, M. Understanding factors associated with teacher-directed student use of technology in elementary classrooms: A structural equation modeling approach. Br. J. Educ. Technol. 2012, 43, 652-666. [CrossRef]

13. Pajares, M.F. Teachers' beliefs and educational research: Cleaning up a messy construct. Rev. Educ. Res. 1992, 62, 307-332 [CrossRef]

14. Altun, D. Investigating pre-service early childhood education teachers' technological pedagogical content knowledge (TPACK) competencies regarding digital literacy skills and their technology attitudes and usage. J. Educ. Learn. 2019, 8, 249-263. [CrossRef]

15. Ertmer, P.; Ottenbreit-Leftwich, A.T. Teacher technology change: How knowledge, confidence, beliefs, and culture intersect. J. Res. Technol. Educ. 2010, 42, 255-284. [CrossRef]

16. Shittu, A.T.; Kareem, B.W.; Obielodan, O.O.; Fakomogbon, M.A. Investigating predictors of pre-service science teachers' behavioral intention toward e-resources for teaching. Contemp. Educ. Technol. 2017, 8, 142-157. [CrossRef]

17. Ertmer, P.A. Addressing first- and second-order barriers to change: Strategies for technology integration. Educ. Technol. Res. Dev. 1999, 47, 47-61. [CrossRef]

18. Ottenbreit-Leftwich, A.; Liao, J.Y.-C.; Sadik, O.; Ertmer, P. Evolution of teachers' technology integration knowledge, beliefs, and practices: How can we support beginning teachers use of technology? J. Res. Technol. Educ. 2018, 50, 282-304. [CrossRef]

19. Prestridge, S. The beliefs behind the teacher that influences their ICT practices. Comput. Educ. 2012, 58, 449-458. [CrossRef]

20. Shulman, L.S. Knowledge and teaching: Foundations of the new reform. Harv. Educ. Rev. 1987, 57, 1-23. [CrossRef]

21. Ball, D.L.; McDiarmid, G.W. The subject-matter preparation of teachers. In Handbook of Research on Teacher Education; Houston, W.R., Sikula, M.H.J., Eds.; Macmillan: New York, NY, USA, 1990; pp. 437-449.

22. Sung, P.-F.; Yang, M.-L. Exploring disciplinary background effect on social studies teachers' knowledge and pedagogy. J. Educ. Res. 2013, 106, 77-88. [CrossRef]

23. Mishra, P.; Koehler, M.J. Technological pedagogical content knowledge: A framework for teacher knowledge. Teach. Coll. Rec. 2006, 108, 1017-1054. [CrossRef]

24. Koehler, M.J.; Mishra, P. What is technological pedagogical content knowledge? Cont. Issues Technol. Teach. Educ. 2009, 9, 60-70. [CrossRef]

25. Scherer, R.; Tondeur, J.; Siddiq, F.; Baran, E. The importance of attitudes toward technology for pre-service teachers' technological, pedagogical, and content knowledge: Comparing structural equation modeling approaches. Comput. Hum. Behav. 2018, 80, 67-80. [CrossRef] 
26. Instefjord, E.J.; Munthe, E. Educating digitally competent teachers: A study of integration of professional digital competence in teacher education. Teach. Teach. Educ. 2017, 67, 37-45. [CrossRef]

27. Keser, H.; Yilmaz, F.G.K.; Yilmaz, R. TPACK competencies and technology integration self-efficacy perceptions of pre-service teachers. Elem. Educ. Online 2015, 14, 1193-1207. [CrossRef]

28. Mei, B.; Brown, G.T.L.; Teo, T. Toward an understanding of preservice English as a foreign language teachers' acceptance of computer-assisted language learning 2.0 in the people's Republic of China. J. Educ. Comput. Res. 2018, 56, 74-104. [CrossRef]

29. Teo, T.; Milutinović, V.; Zhou, M.; Banković, D. Traditional vs. innovative uses of computers among mathematics pre-service teachers in Serbia. Interact. Learn. Environ. 2017, 25, 811-827. [CrossRef]

30. Rienties, B.; Brouwer, N.; Lygo-Baker, S. The effects of online professional development on higher education teachers' beliefs and intentions towards learning facilitation and technology. Teach. Teach. Educ. 2013, 29, 122-131. [CrossRef]

31. Teo, T. Factors influencing teachers' intention to use technology: Model development and test. Comput. Educ. 2011, 57, 2432-2440. [CrossRef]

32. Teo, T.; Lee, C.B.; Chai, C.S.; Wong, S.L. Assessing the intention to use technology among pre-service teachers in Singapore and Malaysia: A multigroup invariance analysis of the Technology Acceptance Model (TAM). Comput. Educ. 2009, 53, 1000-1009. [CrossRef]

33. Teo, T.; van Schaik, P. Understanding the intention to use technology by preservice teachers: An empirical test of competing theoretical models. Int. J. Hum. Comput. Int. 2012, 28, 178-188. [CrossRef]

34. Lai, P.C. The literature review of technology adoption models and theories for the novelty technology. J. Inf. Syst. Technol. Manag. (JISTEM) 2017, 14, 21-38. [CrossRef]

35. Davis, D. A Technology Acceptance Model for Empirically Testing New End-User Information Systems: Theory and results. Ph.D. Thesis, Massachusetts Institute of Technology, Cambridge, MA, USA, 1986. Available online: https://dspace.mit.edu/ handle/1721.1/15192 (accessed on 25 February 2021).

36. Teo, T.; Huang, F.; Hoi, C.K.W. Explicating the influences that explain intention to use technology among English teachers in China. Interact. Learn. Environ. 2018, 26, 460-475. [CrossRef]

37. Prestridge, S.; de Aldama, C. A classification framework for exploring Technology-Enabled Practice-Frame TEP. J. Educ. Comput. Res. 2016, 54, 901-921. [CrossRef]

38. Tondeur, J.; van Braak, J.; Ertmer, P.A.; Ottenbreit-Leftwich, A. Understanding the relationship between teachers' pedagogical beliefs and technology use in education: A systematic review of qualitative evidence. Educ. Technol. Res. Dev. 2016, 65, 555-575. [CrossRef]

39. Inan, F.A.; Lowther, D.L. Laptops in the K-12 classrooms: Exploring factors impacting instructional use. Comput. Educ. 2010, 55, 937-944. [CrossRef]

40. Luik, P.; Taimalu, M. Professional knowledge clusters of student teachers based on the TPACK framework. Teach. Teach. 2020. submitted.

41. Schreiber, J.B.; Stage, F.K.; King, J.; Nora, A.; Barlow, E.A. Reporting structural equation modeling and confirmatory factor analysis results: A review. J. Educ. Res. 2006, 99, 323-337. [CrossRef]

42. Kline, R.B. Principles and Practice of Structural Equation Modelling, 3rd ed.; Guilford Press: New York, NY, USA, 2011.

43. Bentler, P.M.; Bonett, D.G. Significance tests and goodness of fit in the analysis of covariance structures. Psychol. Bull. 1980, 88, 588-606. [CrossRef]

44. Brown, T.A. Confirmatory Factor Analysis for Applied Research; Guilford Press: New York, NY, USA, 2006.

45. Hu, L.; Bentler, M.P. Cutoff criteria for fit indexes in covariance structure analysis: Conventional criteria versus new alternatives. Struct. Equ. Model. 1999, 6, 1-55. [CrossRef]

46. Hair, J.F.; Black, W.C.; Babin, B.J.; Anderson, R.E. Multivariate Data Analysis; Pearson Education Limited: London, UK, 2013.

47. Fornell, C.; Larcker, D.F. Evaluating structural equation models with unobservable variables and measurement error. J. Mark. Res. 1981, 18, 39-50. [CrossRef]

48. Henseler, J.; Ringle, C.M.; Sarstedt, M. A new criterion for assessing discriminant validity in variance-based structural equation modeling. J. Acad. Mark. Sci. 2015, 43, 115-135. [CrossRef]

49. Voorhees, C.M.; Brady, M.K.; Calantone, R.; Ramirez, E. Discriminant validity testing in marketing: An analysis, causes for concern, and proposed remedies. J. Acad. Mark. Sci. 2015, 44, 119-134. [CrossRef] 